\title{
Research on Marketization Process and Innovation Efficiency of Guangdong-Hong Kong-Macao Greater Bay Area-Spatial Autocorrelation Model Based on Geography and Network Weighting
}

\author{
Li Fu \\ Jinan University, Guangzhou, China \\ Email:1ifu0407@163.com
}

How to cite this paper: Fu, L. (2020). Research on Marketization Process and Innovation Efficiency of Guangdong-Hong Kong-Macao Greater Bay Area-Spatial Autocorrelation Model Based on Geography and Network Weighting. Modern Econo$m y, 11,349-367$.

https://doi.org/10.4236/me.2020.112027

Received: October 28, 2019

Accepted: February 14, 2020

Published: February 17, 2020

Copyright $\odot 2020$ by author(s) and Scientific Research Publishing Inc. This work is licensed under the Creative Commons Attribution International License (CC BY 4.0).

http://creativecommons.org/licenses/by/4.0/

\section{(c) (i) Open Access}

\begin{abstract}
This paper uses the Malmquist index method to measure the innovation efficiency of Guangdong-Hong Kong-Macao Greater Bay Area in 2009-2016, and decomposes the innovation efficiency into resource allocation efficiency and technological progress rate. It is found that the efficiency of innovation and allocation in Guangdong-Hong Kong-Macao Greater Bay Area shows a steady growth trend. The cities on the west bank of the Guangdong-Hong Kong-Macao Greater Bay Area are more obvious, but in general, the cities on east coast of Guangdong-Hong Kong-Macao Greater Bay Area have higher comprehensive efficiency and technological progress. On this basis, the spatial measurement method is used to demonstrate the impact of the marketization process of Guangdong-Hong Kong-Macao Greater Bay Area on its innovation efficiency. The empirical results show that the marketization process has a significant role in promoting the innovation efficiency of Guangdong-Hong Kong-Macao Greater Bay Area. And there are certain regional differences. The innovation efficiency of the cities on the west bank of the Guangdong-Hong Kong-Macao Greater Bay Area is more significantly affected by the marketization process, while the East Coast cities are more sensitive to changes in economic density and industrial structure. In addition, there is a certain positive spatial correlation between innovation efficiency, especially in the east coast cities of Guangdong-Hong Kong-Macao Greater Bay Area. The cities with high innovation efficiency show a certain geographical concentration distribution, indicating that the regions with high innovation efficiency have certain promotion to innovation efficiency of neighboring regions.
\end{abstract}


Keywords

Marketization, Innovation Efficiency, Guangdong-Hong Kong-Macao Greater Bay Area

\section{Introduction}

Guangdong-Hong Kong-Macao Greater Bay Area is the fourth largest Bay Area in the world after San Francisco Bay Area, New York Bay Area and Tokyo Bay Area. It is an important demonstration area for China's comprehensive opening strategy. It was in 2017 work report of the State Council that the "Research and Formulation of the Development Plan for the City Group of Guangdong, Hong Kong, Macao and Macao" marked the official rise of the Guangdong-Hong Kong-Macao Greater Bay Area as a national strategy. Its important goal is to create a global innovation highland and to play a leading role in the national innovation-driven strategy of the Guangdong-Hong Kong Greater Bay Area urban agglomeration. Therefore, the construction of the Bay Area places special emphasis on industrial innovation and integration. In 2016, Guangdong, Hong Kong and Macau's Greater Bay Area has a total production area of 1.4 trillion yuan. It has 16 Fortune 500 companies and 30,000 state-level high-tech enterprises. It has a good foundation for creating innovative Bay Area, especially in terms of innovation capability. Hong Kong and Macau's Greater Bay Area has maintained strong growth momentum in recent years. According to the 2017 Global Innovation Index Report, the Guangdong-Hong Kong Greater Bay Area Innovation Index ranked second. Another data show that: the number of Greater Bay Area's invented patent applications is increasing year by year in 2009-2016. In 2016, the number of invention patent applications in Guangdong, Hong Kong and Macau's Greater Bay Area reached 19,000, which has surpassed the San Francisco Bay Area and the gap is widening. It should be noted that compared with other Bay Areas, Guangdong-Hong Kong-Macao Greater Bay Area has a large scale advantage, but there is still a big gap in efficiency. In 2016, the per capita GDP of Guangdong-Hong Kong-Macao Greater Bay Area was US $\$ 20084 /$ person. It is only $1 / 5$ of San Francisco, far lower than the other three major Bay Areas. At the same time, this difference in efficiency is more reflected in the ability to innovate. As China's R \& D investment continues to increase, the current problems in China's innovation have been shifted by scale. For innovation redundancy (Chen \& Dai, 2018), no matter in the stage of innovation input and output or the stage of achievement transformation, low efficiency will directly affect the sustainable growth of China's innovation ability, so how to improve innovation efficiency is guaranteed Guangdong-Hong Kong-Macao Greater Bay Area's innovation capacity is sustainable and further narrows the gap between other Bay Areas. Classical economics believes that the market is the most effective way of resource allocation. For China in the process of economic 
restructuring, market-oriented institutional reform and improvement are important factors affecting innovation efficiency (Farrell, 1957). Therefore, this paper constructs an empirical model from the perspective of the market-oriented main body reform process to analyze the impact of the marketization process of Guangdong-Hong Kong-Macao Greater Bay Area on its innovation efficiency.

\section{Literature Review and Theoretical Hypothesis}

Farrell (1957) first proposed the idea of envelope in the study of British agricultural productivity, and believed that the input-output ratio is closely related to the production possibility boundary, and the innovation efficiency is decomposed into the allocation efficiency and technical efficiency of the innovation resource. The ratio of actual output to maximum output under the same set of inputs (Farrell, 1957); domestic research on innovation efficiency is mainly focused on the measure of innovation efficiency. Guan Jiancheng and Chen Kaihua (2009) use the data envelopment method to measure the technical efficiency, pure technical efficiency and scale efficiency of China's high-tech industry in technological innovation activities have found that the pure technical efficiency of China's high-tech industry is improving year by year, but the scale efficiency is weakening year by year (Guan \& Chen, 2009). In addition to the use of data envelopment methods, some scholars use stochastic frontier analysis methods to measure the innovation efficiency of high-tech enterprises in China. For example, Han Jing (2010) used SFA to analyze the innovation efficiency of high-tech industries in different industries in China, and found that the equipment manufacturing industry with the lowest innovation efficiency, electronic computers and related industries have the highest innovation efficiency (Han, 2010). So what are the main factors affecting the improvement of China's innovation efficiency? There are some differences in the marketization process in different regions (Fan \& Wang, 2011), so the macro-environment and conditions faced by enterprises in various regions are different (Fan \& Wang, 2011). For countries in the process of economic restructuring, market-oriented institutional reform and improvement are important factors affecting the efficiency of innovation (Cheng \& Sun, 2012). Wu Yanbing (2006) focused on the impact of property rights system on innovation efficiency in the process of market-oriented reform. Compared with other property-type enterprises, state-owned enterprises have the lowest innovation performance $(\mathrm{Wu}, 2006)$. Foreign research mainly focuses on the impact of factors such as firm size and market power on corporate innovation performance. For example, Villard (1958) found that enterprises are more inclined to increase $\mathrm{R} \& \mathrm{D}$ investment as the scale of enterprises increases (Villard, 1958); Scherer (1957) found the characteristics of the inverse U-shaped function relationship between market concentration and R \& D input (Scherer, 1957). Generally speaking, a centralized economy with soft budget constraints has a hindrance to innovation (Huang \& Xu, 1998), which can be summarized as the following four points. 1) In a highly centralized economy, soft budget con- 
straints encourage entrepreneurs to innovate resources. More investment in the area of rent-seeking will lead to new product innovation investment and innovation performance decline. Unlike the centralized economy, the rich returns and competitive pressures of innovation success in a free market economy have prompted entrepreneurs to relentlessly improve their innovation performance. 2) When deploying innovative resources, state-owned enterprises are more favored by the government. In the capital market, due to government endorsement, they face fewer financing constraints than non-state-owned enterprises, and the defects of state-owned enterprises' incentive mechanisms, and Problems such as lax supervision are serious, and there are serious principal-agent problems. Blind and excessive investment problems are easy to exist in the R \& D process. 3) On the other hand, in a place with a low market level, the problem of information asymmetry between enterprises and investors is more serious, distorting the price of factor markets, mismatching innovation resources, and causing serious efficiency losses, greatly inhibited the improvement of innovation efficiency. 4) Marketization provides enterprises with the power of innovation. Under the perfect property rights system, enterprises can obtain huge profits brought by technological innovation, so that enterprises can pay more attention to the research and development of core technologies in order to gain market competitiveness. It is of great positive significance to promote the effective allocation of innovative resources.

Although the marketization process may have a very important impact on resource allocation efficiency, especially innovation efficiency, domestic scholars pay little attention to this, especially the empirical research on market efficiency for innovation efficiency. Most scholars are concerned about marketization, the impact of China's economic growth and income gap (Shi \& Wang, 2016; Deng \& $\mathrm{He}, 2017)$. Only a few scholars have tried to study the marketization and innovation efficiency: Dai Kuiqian and Liu Youjin (2013) based on the panel data of China's high-tech industry from 1995 to 2010, using the GMM method to empirically examine the marketization process for innovation efficiency, impact and industry differences. It is found that the effect of marketization process on innovation efficiency is related to industry characteristics. In industries with low technology intensity and high degree of extroversion, the marketization process has a greater positive impact on innovation efficiency (Dai \& Liu, 2013); Sun Zao et al. (2014) The perspective of local government protectionism explores the impact of marketization process on $\mathrm{R} \& \mathrm{D}$ spillovers, and finds that market-oriented reforms have increased $\mathrm{R} \& \mathrm{D}$ spillovers, especially when the marketization of sources is low, and the degree of marketization of spillover acceptance increases $\mathrm{R}$ \& D spillovers. The promotion is particularly evident (Sun, Liu, \& Sun, 2014).

Although some scholars have done some research, the previous literature has not paid enough attention to the marketization process and innovation efficiency. The empirical research done only stays at the provincial level, ignoring the impact of regional heterogeneity on the model. Even if many control variables or 
spatial measurement methods are adopted, it is difficult to eliminate the influence of some factors that are difficult to quantify. For example, the differences caused by factors such as culture and climate are often ignored by the model. In this case, the model the conclusion is unreliable. The efficiency of innovation is affected by many factors. The degree of marketization in different regions is different, and the degree of influence on innovation efficiency is different. Therefore, focusing on a small area can eliminate the influence of some variables, and it can also be more prominent. It can also be more prominent to figure out the role of the target variable in the study. On the other hand, in the past literature, the spatial dependence of innovation spillovers is often considered only by considering the influence of the subject's spatial characteristics such as distance or proximity. In fact, with the rapid development of the Internet and mobile electronic communication technologies, different regions various elements or information exchanges often do not need to rely on physical space, but are more dependent on the role of cyberspace, and such cyberspace is not homogeneous like geospatial, but the reasons for this heterogeneity are different. One of the main reasons for the inhomogeneity of physical space is the existence of transportation costs, and the reason for the uneven network space comes from the difference of flow or heat. The flow size or heat information between different regions just reflects each other. The degree of contact greatly weakens the impact of distance in physical space. Therefore, it is necessary to distinguish the roles of these two spaces when considering the spatial correlation of variables in the empirical model. Especially for innovative activities, the Internet makes the sharing of knowledge and the exchange of ideas so convenient, affecting innovation. The effects of cyberspace should not be overlooked when spillover effects occur. Guangdong-Hong Kong-Macao Greater Bay Area is the most market-oriented region in China. In particular, Shenzhen has always been the pioneer of China's market-oriented reforms, and is also the region with the most active innovation activities in China. The choice of Guangdong-Hong Kong-Macao Greater Bay Area as a research object can highlight marketization. The relationship between process and innovation efficiency also makes research more realistic. This paper selects the innovation activity data of Guangdong-Hong Kong-Macao Greater Bay Area from 2009-2016 to construct the DEA-malmquist index to measure the innovation efficiency of Greater Bay Area, and builds a spatial measurement model to further explore the impact of marketization process on the innovation efficiency of Guangdong and Hong Kong's Greater Bay Area. At the same time, when considering the spatial effect, not only the geospatial space, but also the impact of cyberspace on innovation spillovers.

\section{Based on the Malmquist Index of Innovation Efficiency and Its Decomposition}

The Malmquist index is used to study the efficiency change of decision making unit (DMU) in different periods. It is a typical non-parametric estimation me- 
thod. The advantage is that it does not need to determine the form of production function in advance, nor does it need to dimensionless input-output data. It can be adapted to the situation of multi-input and multi-output, and is widely used in the field of calculating production efficiency.

Assumption:

$\left(X_{j 0}^{t}, Y_{j 0}^{t}\right)$ Represents the input-output configuration of the decision-making unit in the $t$ period, which $X$ represents the production input set and $Y$ represents the production output set.

$F_{j 0}^{t}\left(X_{j 0}^{t}, Y_{j 0}^{t}\right)$ represents the technical efficiency of the decision-making unit with the input-output data of the t-term. The conditions for maximizing the overall efficiency of the decision unit during the $t$ period are:

$$
\begin{gathered}
F_{j 0}^{t}\left(X_{j 0}^{t}, Y_{j 0}^{t}\right)=\min \theta \\
\mathrm{st}=\left\{\begin{array}{l}
\sum_{j=1}^{n} \lambda_{j} X_{j}^{t} \leq \theta X_{j 0}^{t} \\
\sum_{j=1}^{n} \lambda_{j} Y_{j}^{t} \leq Y_{j 0}^{t} \\
\lambda_{j} \geq 0, j=0,1,2, \cdots, n
\end{array}\right.
\end{gathered}
$$

$\frac{F_{j 0}^{t}\left(X_{j 0}^{t+1}, Y_{j 0}^{t+1}\right)}{F_{j 0}^{t}\left(X_{j 0}^{t}, Y_{j 0}^{t}\right)}$ indicates the efficiency change rate of the production activities calculated by the decision-making unit based on the input-output data of the t-term from the $\left(X_{j 0}^{t}, Y_{j 0}^{t}\right)$ change to the $\left(X_{j 0}^{t+1}, Y_{j 0}^{t+1}\right)$. The Malmquist index refers to the ratio of the change of the distance function of the frontier surface of the technology from time $t+1$ to time $t$, which is given by the following formula:

$$
M_{j 0}^{t+1}\left(X_{j 0}^{t+1}, Y_{j 0}^{t+1}, X_{j 0}^{t}, Y_{j 0}^{t}\right)=\left[\frac{F_{j 0}^{t}\left(X_{j 0}^{t+1}, Y_{j 0}^{t+1}\right)}{F_{j 0}^{t}\left(X_{j 0}^{t}, Y_{j 0}^{t}\right)} \cdot \frac{F_{j 0}^{t+1}\left(X_{j 0}^{t+1}, Y_{j 0}^{t+1}\right)}{F_{j 0}^{t+1}\left(X_{j 0}^{t}, Y_{j 0}^{t}\right)}\right]^{\frac{1}{2}}
$$

It reflects the efficiency change of decision-making unit from $t$ period to $t+1$ period, which can be further decomposed into resource allocation efficiency AC and technological progress rate TC. Resource allocation efficiency refers to the production of given output under given price and technical level. The optimal input combination, the rate of technological progress refers to the ratio of actual output to maximum output under the given input factors.

$$
\begin{gathered}
M_{j 0}^{t+1}\left(X_{j 0}^{t+1}, Y_{j 0}^{t+1}, X_{j 0}^{t} Y_{j 0}^{t}\right)=T C_{j}^{t+1}\left(Y^{t+1}, X^{t+1}, Y^{t}, X^{t}\right) \cdot E C_{j}^{t+1}\left(Y^{t+1}, X^{t+1}, Y^{t}, X^{t}\right) \\
T C_{j}^{t+1}\left(Y^{t+1}, X^{t+1}, Y^{t}, X^{t}\right)=\left[\frac{F_{j}^{t}\left(Y^{t+1}, X^{t+1}\right)}{F_{j}^{t+1}\left(Y^{t+1}, X^{t+1}\right)} \cdot \frac{F_{j}^{t}\left(Y^{t}, X^{t}\right)}{F_{j}^{t+1}\left(Y^{t}, X^{t}\right)}\right]^{\frac{1}{2}} \\
E C_{j}^{t+1}\left(Y^{t+1}, X^{t+1}, Y^{t}, X^{t}\right)=\frac{F_{j}^{t+1}\left(Y^{t+1}, X^{t+1}\right)}{F_{j}^{t}\left(Y^{t}, X^{t}\right)}
\end{gathered}
$$

This paper selects the 2009-2016 innovation input and output data of various cities in Guangdong, Hong Kong and Macao, and (excluding Macao due to the 
availability of Macao data), R \& D personnel of industrial enterprises, R \& D expenses of industrial enterprises, and government finance. As a source of innovation investment, the expenditure of financial science and technology is based on the number of patent applications and the output value of high-tech products as the output vector. The innovative Malmquist index of each city in Guangdong, Hong Kong and Macao is calculated using R 3.4.3. The data of each indicator are from the Guangdong and Hong Kong. The statistical yearbooks for the cities of the Bay Area (excluding Hong Kong) for 2010-2017, the missing data for some regions and years are supplemented by the Guangdong Science and Technology Innovation Statistical Yearbook; Hong Kong data comes from the Hong Kong Statistical Yearbook 2010-2017 and Hong Kong Statistics on Innovation Activities; All the statistical yearbooks are data for the previous year. The average value of innovation efficiency of each city in Guangdong, Hong Kong and Macau in 2009-2016 will be compiled as shown in Table 1 .

1) The results of Malmquist show that the comprehensive efficiency values of all cities except Guangdong, Hong Kong and Guangzhou in Guangdong, Hong Kong and Macao are less than 1, indicating that the overall efficiency of innovation has shown a certain downward trend, mainly due to the slow growth of technological progress; However, from the time dimension (shown in Figure 1), the growth rate of technological progress has contributed more to the growth of overall efficiency, accounting for 70\%; While the efficiency of innovation resource allocation in the cities of Guangdong, Hong Kong and Macao is significantly higher than the rate of technological progress, and has reached one. A relatively high level, but limited growth space and power, contribute less to the improvement of the comprehensive efficiency of innovation in Greater Bay Area.

2) Grouping the cities of Greater Bay Area on the east coast or the west bank of the Pearl River. The east coast (East for short) includes Guangzhou, Shenzhen, Hong Kong, Huizhou and Dongguan. The west coast (West for short) includes Zhuhai, Foshan, Zhongshan, Jiangmen and Zhaoqing. It can be seen that the East Coast is slightly larger in the West Bank in terms of overall efficiency of innovation, and this gap is reflected in the rate of technological progress. The

Table 1. Average of innovation efficiency of various cities in Guangdong, Hong Kong and Macau in 2009-2016.

\begin{tabular}{ccccccc}
\hline Region & Zhu Hai & Zhong Shan & Zhao Qin & Hong Kong & Shen Zhen & Jiang Men \\
\hline M & 0.9952 & 0.9533 & 0.8684 & 1.0023 & 1.3045 & 0.8930 \\
TC & 0.9248 & 0.9744 & 0.8684 & 1.0282 & 1.2200 & 0.8930 \\
EC & 1.0871 & 0.9752 & 1.0000 & 1.0004 & 1.1098 & 1.0000 \\
\hline Region & Hui Zhou & Guang Zhou & Fo Shan & Dong Guan & West & East \\
\hline M & 0.9560 & 1.0765 & 0.9582 & 0.7831 & 0.9336 & 1.0245 \\
TC & 0.9560 & 1.0765 & 0.8984 & 0.8715 & 0.9118 & 1.0304 \\
EC & 1.0000 & 1.0000 & 1.0817 & 0.8853 & 1.0288 & 0.9991 \\
\hline
\end{tabular}




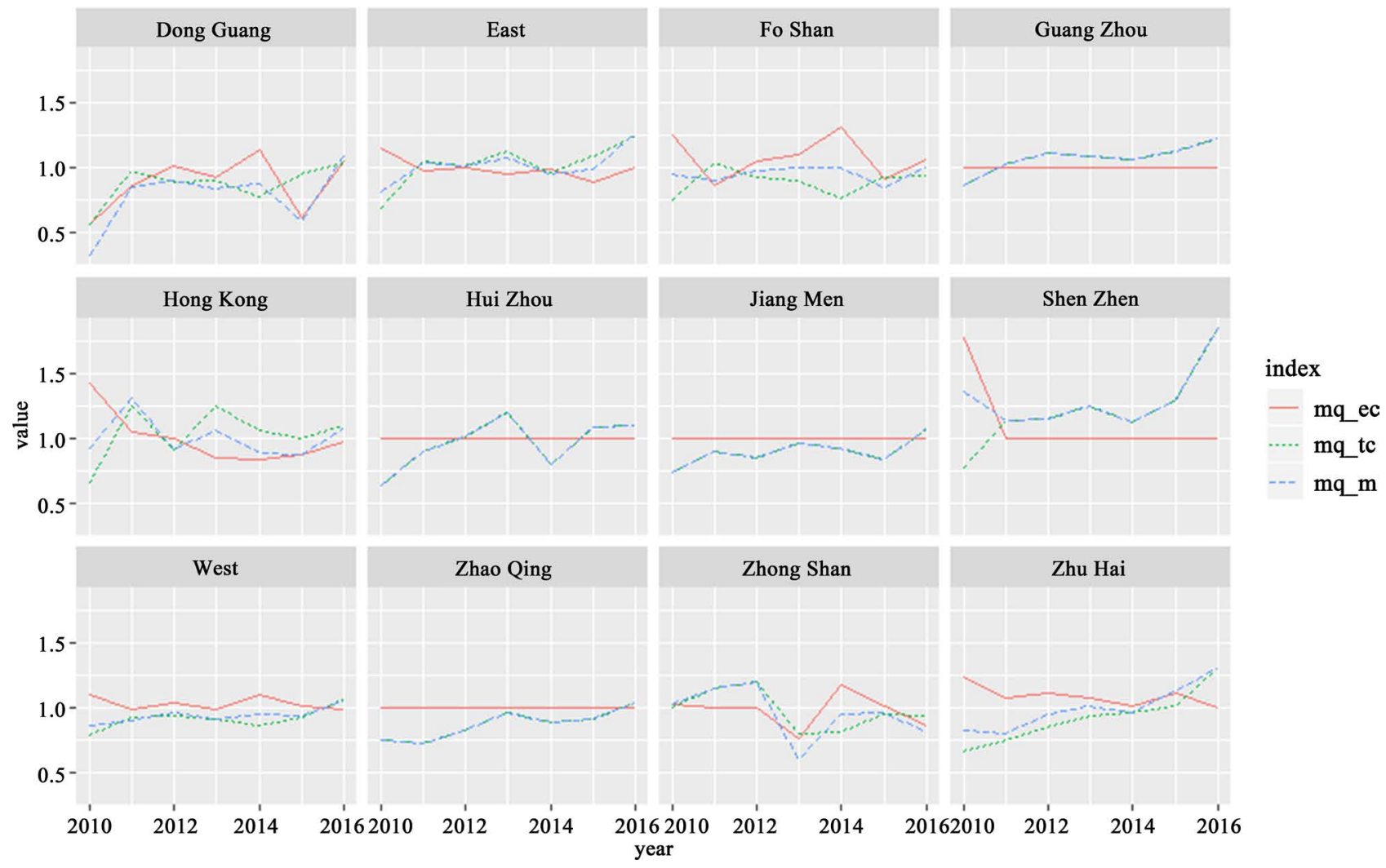

Note: mq_ec: innovative configuration efficiency; mq_tc: innovative technology efficiency; mq_m: innovative overall efficiency.

Figure 1. Decomposition of innovation efficiency in 2010-2016 in Cities of Guangdong-Hong Kong-Macao Greater Bay Area.

East Coast has higher average technical efficiency than the West Bank and has lower resource allocation efficiency, and East of 2010-2016. The efficiency of resource allocation on the shore is declining year by year. This shows that the East Coast is stronger than the West Bank in terms of innovation and technological capabilities, but it is more likely to invest resources than the West Bank, resulting in a relatively unprofessional scale in resource allocation, under established scale and technical conditions. As the growth of investment growth, output growth cannot be proportionally increased. This also means that the higher the economic level, the higher the efficiency of innovation resource allocation, and the high density of innovative resource agglomeration may bring about the problem of redundant resources.

\section{Variables, Data, Models}

\section{1) Variable selection}

From the above analysis, it can be seen that the innovative Malmquist comprehensive index of each city in Guangdong, Hong Kong and Macau is reflecting the change of innovation resource allocation efficiency and innovation technology efficiency. This paper uses Malmquist index to measure the change of innovation efficiency, which is represented by the letter MQ. The marketization process is the core explanatory variable of this paper. The measurement of the 
degree of marketization in the past literature some scholars directly quoted China's provincial marketization index in the "China Marketization Index Report" compiled by Fan Gang and Wang Xiaolu, but the marketization of this set. The index is only subdivided into the provincial level, and its research value is limited when further research on smaller regional units; the marketization process is mainly reflected in the development of non-state-owned economy (Fan \& Wang, 2011), thus reflecting the marketization process. The important indicator is the proportion of market-oriented entities in the national economy. Some scholars (Sun et al., 2014) use the ratio of the total industrial output value of non-state-owned enterprises to the total output value of state-owned enterprises to measure the degree of marketization in different regions (Segal, 1976). Taking into account the availability of data, this paper represents the marketization process by the ratio of the total output value of non-state-owned industrial enterprises to the total output value of state-owned enterprises, expressed by the letter DOM. The other control variables are selected as follows:

Economic density (DOP), research on economic density mainly focuses on the relationship between economic density and total factor productivity. It is generally believed that the increase in urban density has a significant effect on the improvement of urban productivity (Segal, 1976; Ciccone et al., 2006), but the performance of urban innovation capability is not consistent with the performance of economic growth. The effect of economic density on urban innovation efficiency and the effect of economic density on urban productivity have different effects (Ge, 2018), population There may be an 'inverted U' relationship between aggregation and regional innovation efficiency (Chen \& Yang, (2017). In any case, most studies have shown that economic density has an important impact on regional innovation activities. The higher the population density, the higher the density of economic activities. Considering the availability of data, the population density of each city in Guangdong, Hong Kong and Macao is used as a proxy variable for economic density.

The degree of openness (OPEN), a large number of studies show that a country's improvement of foreign trade can significantly promote the improvement of innovation efficiency (Wang, Lai, \& Qi, 2010; Zhu \& Wang, 2015), of course, some scholars This questioned that the improvement of foreign trade level has an inhibitory effect on innovation efficiency (Woerter and Roper, 2010; Handan University, 2013) (Kan, 2013). This paper uses the proportion of the total import and export volume of the region and the regional GDP as a proxy variable for the degree of openness.

Industrial structure (SOI) and economic development level (GDP), the higher the economic development of a place, the better the development of infrastructure, education, finance and other service industries, especially the development of the financial industry has a significant impact on regional innovation capabilities (Schumpeter \& Nichol, 1934; Zhao, Zhou, \& Shen, 2016; Yang \& Cheng, 2018). Therefore, this paper takes the industrial structure and economic devel- 
opment level as the control variables, and takes the proportion of the tertiary industry's GDP to the regional GDP as a pair. The measurement of industrial structure, GDP as a measure of the level of economic development, of course, according to the first Clarke theorem, there may be a very high correlation between the industrial structure and economic development level of a region. In order to avoid the influence of multicollinearity, one of them will be selected as the control variable in the actual model.

\section{2) Descriptive statistics}

In order to facilitate the comparison between the variables calculated by different units, the regional GDP data is dimensionless. Table 2 gives a description of each variable and descriptive statistics.

It can be seen from Table 2 that the average value of MQ is less than 1, indicating that the overall innovation efficiency of Guangdong-Hong Kong-Macao Greater Bay Area is slowly decreasing, and its standard deviation is 0.2159 , indicating that the innovation efficiency varies greatly in different regions or different periods, such as economic development. There are also significant differences between the regions of the variables such as level and population density. The standard deviation of OPEN is the smallest, which is 0.0181 , which indicates that the economic development level of Guangdong-Hong Kong-Macao Greater Bay Areas is not much different. Of course, all indicators are only in Guangdong. Comparing the internals of Hong Kong and Macau's Greater Bay Area, the gap between the variables shows a relative gap rather than an absolute gap. Meanwhile as it can be seen from the comparison of Figure 2 and Figure 3 that regions with a high degree of marketization also have higher innovation efficiency. We can assume that the degree of marketization has some positive effect on innovation efficiency.

\section{3) Model setting}

The spatial measurement model is widely used at home and abroad. The two most common forms are the spatial autocorrelation model (SAC) and the spatial error model (SEC). It is generally believed that the innovation activities of a region are always affected by the innovation activities in the neighboring regions. The spatial econometric model can be used to identify this influence and make

Table 2. Description of variables.

\begin{tabular}{ccccccc}
\hline Var & MQ & DOM & DOP & OPEN & SOI & GDP \\
\hline Meaning & $\begin{array}{c}\text { Malquist } \\
\text { Index }\end{array}$ & Markelization & $\begin{array}{c}\text { Dense of } \\
\text { Population }\end{array}$ & Openness & $\begin{array}{c}\text { Industrial } \\
\text { Structure }\end{array}$ & $\begin{array}{c}\text { Gross Domestic } \\
\text { Production }\end{array}$ \\
\hline Mean & 0.9682 & 0.9613 & 0.3226 & 0.0367 & 0.4599 & 0.2685 \\
Max & 1.8477 & 0.9613 & 0.3226 & 0.0367 & 0.4599 & 1.0000 \\
Min & 0.3229 & 0.9613 & 0.3226 & 0.0367 & 0.4599 & 0.0000 \\
Medium & 0.9491 & 0.9731 & 0.3247 & 0.0282 & 0.4288 & 0.1150 \\
Std & 0.2159 & 0.0500 & 0.2549 & 0.0181 & 0.0952 & 0.2879 \\
\hline
\end{tabular}




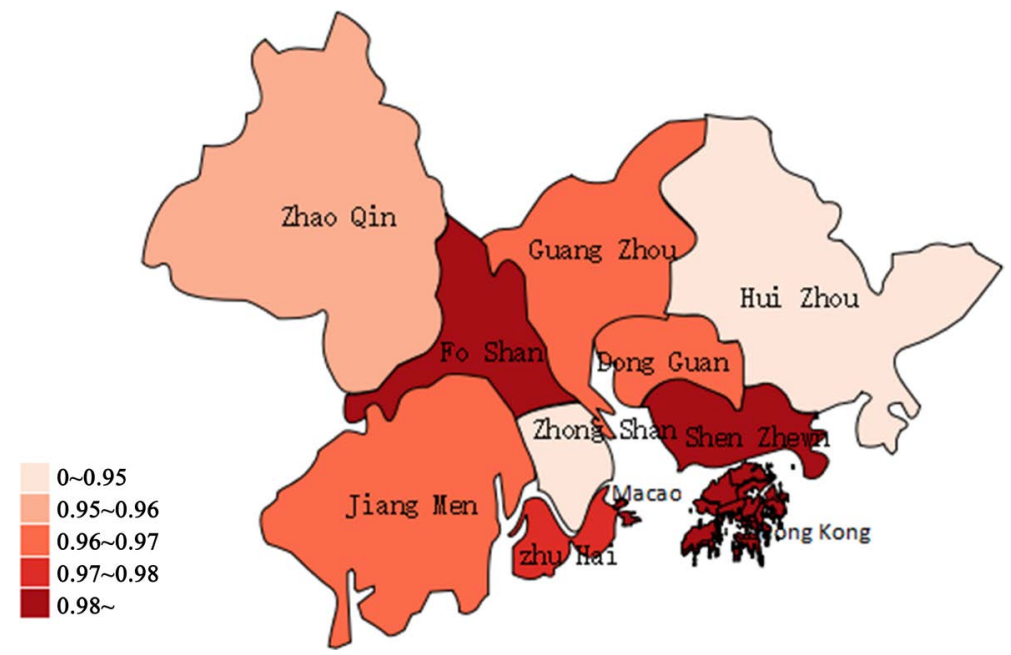

Figure 2. Mean distribution of marketization process in Greater Bay Area of Guangdong, Hong Kong and Macau.

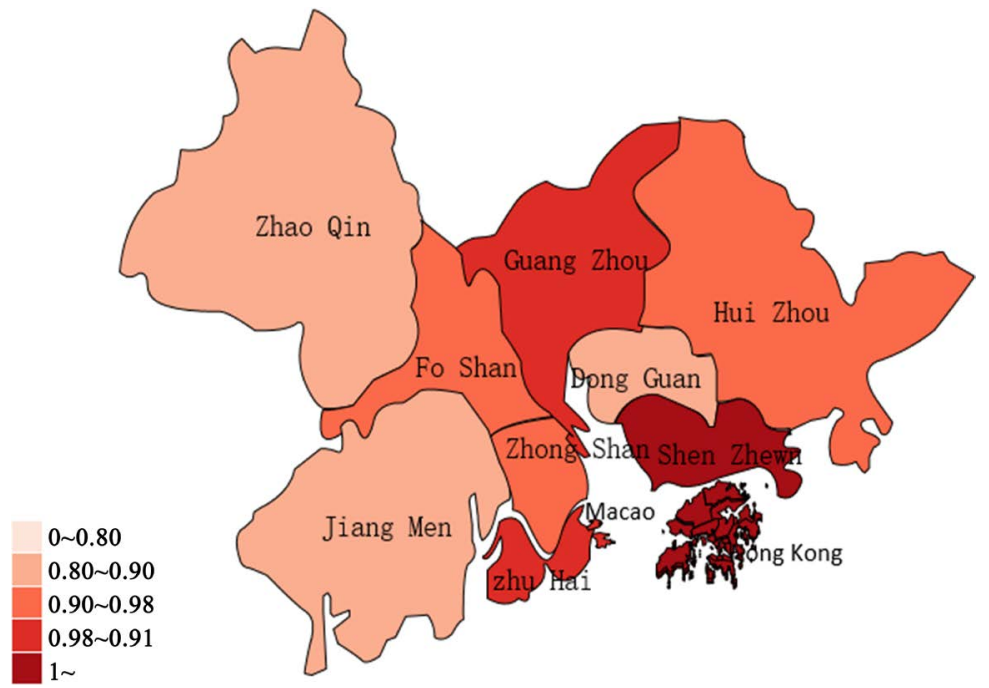

Figure 3. Distribution of innovation efficiency in Greater Bay Area of Guangdong and Hong Kong.

the estimation of the model parameters more accurate. Therefore, the model is set as the following spatial autocorrelation model:

$$
\begin{aligned}
M Q_{i t}= & \alpha_{0}+p W \times M Q_{i t}+\alpha_{1} D O M_{i t}+\alpha_{2} D O P_{i t} \\
& +\alpha_{3} O{ } N_{i t}+\alpha_{4} S O I_{i t}+\alpha_{5} G D P_{i t}+\varepsilon_{i t}
\end{aligned}
$$

$M Q_{i t}, D O M_{i t}, D O P_{i t}, O P E N_{i t}, S O I_{i t}, G D P_{i t}$ respectively indicate the innovation efficiency value, marketization degree, economic density, openness, industrial structure, and economic development level of the i-th region in the $\mathrm{t}$-th year; represent the spatial weight, this paper uses the spatial adjacency matrix (0 - 1 space) Matrix, spatial distance matrix, network space matrix as spatial weight value; spatial adjacency matrix means take 1 when two regions are adjacent, 0 when not adjacent; spatial distance matrix uses the reciprocal of the square of the distance between regions as the weight; The distance between the 
major high-speed rail stations is measured by the linear distance between the major high-speed rail stations. The kilometer is used as the unit of measurement. The data comes from Baidu map; the cyberspace matrix uses the inter-regional Baidu index as the weight. Baidu Index (Baidu Index) is based on the behavior data of Baidu's massive netizens, reflecting the Internet's heat and traffic information in various regions. Therefore, Baidu Index can be used to measure the degree of contact between different regions in the network.

Spatial matrix

$$
\begin{gathered}
w_{i j}= \begin{cases}1, & i \text { adjacent to } j \\
0, & i \text { not adjacent to } j\end{cases} \\
w_{i j}^{d}= \begin{cases}\frac{1}{d_{i j}^{2}}, & i \neq j \\
0, & i=j\end{cases} \\
w_{i j}^{b}= \begin{cases}b_{i j}, & i \neq j \\
0, & i=j\end{cases}
\end{gathered}
$$

\section{Empirical Analysis}

\section{1) Spatial correlation test}

The Moran'I index is widely used for the test of spatial correlation, and its expression is as follows:

$$
\operatorname{MoranI}=\frac{\sum_{i=1}^{n} \sum_{j=1}^{n} w_{i j}\left(y_{i}-\bar{y}\right)\left(y_{j}-\bar{y}\right)}{S^{2} \sum_{i=1}^{n} \sum_{j=1}^{n} w_{i j}} \quad S^{2}=\frac{1}{n} \sum_{i=1}^{n}\left(y_{i}-\bar{y}\right)^{2}, \bar{y}=\frac{1}{n} \sum_{i=1}^{n} y_{i}
$$

where $y_{i}$ represents the $i$-th regional innovation efficiency value, $n$ represents the total number of regions, $W$ represents the spatial weight matrix; Moran'I index has a value range of $[-1,1]$.

When Moran'I > 0, it means that the innovation efficiency is spatially positive correlation, that is, the area with the same innovation efficiency is spatially agglomerated, and the larger the value, the more obvious the correlation; when Moran'I < 0, the representation space Negative correlation, the larger the value indicates that the spatial difference of innovation efficiency is more obvious. When Moran'I $=0$, it means that there is no spatial correlation, that is, the size of innovation efficiency is spatially random distribution. As can be seen from Table 3, Moran'I $=0.246$, indicating that the innovation efficiency of each region of Guangdong-Hong Kong-Macao Greater Bay Area is mutually influential, and the improvement of innovation efficiency in a region may not only be affected by its own factors, but also may be affected by proximity. The role of regional innovation efficiency, and this role is positive, the region with higher innovation efficiency can always promote the improvement of innovation efficiency in its neighboring regions, that is, there is spillover effect. 


\section{2) Results of spatial measurement model}

Considering that the results of the Moran'I index cannot reject the spatial autocorrelation of innovation efficiency, this paper will use the spatial measurement method to construct the econometric model, and use the Hausen test value to determine whether to use the fixed effect (fe) or the random effect model (re). The endogenous processing of variables uses the 2SLS method, which considers three spatial matrices for weighting, and uses Stata14 for estimation. First, we discuss the results of regression in the Guangdong-Hong Kong-Macao Greater Bay Area, and obtain nine models of M1 - M9, and the results will be finished as shown in Table 4 below.

1) According to Table 4, except for Model 9 (M9), the spatial regression coefficient is significantly positive, indicating that there is a significant spatial spillover of innovation efficiency. The improvement of innovation efficiency in one region will obviously promote the innovation efficiency of surrounding areas, and innovation. High-efficiency areas show a certain amount of spatial agglomeration. The comparison of groupings with different spatial weight matrices shows that the spatial correlation coefficient of the geographic distance matrix estimation is significantly higher than that of the other two matrix estimations,

Table 3. Moran'I test results.

\begin{tabular}{ccccc}
\hline Variables & Moran'I & SD (Moran') & Z_Value & P_Value \\
\hline MQ & 0.246 & 0.11 & 3.099 & 0.02 \\
\hline
\end{tabular}

Table 4. Overall regression results of the SAC model.

\begin{tabular}{|c|c|c|c|c|c|c|c|c|c|}
\hline \multirow{2}{*}{$\begin{array}{c}\text { Mat_Type } \\
\text { Variable }\end{array}$} & \multicolumn{3}{|c|}{ Geographic proximity matrix } & \multicolumn{3}{|c|}{ Geographic distance matrix } & \multicolumn{3}{|c|}{ Cyberspace matrix } \\
\hline & M1 & M2 & M3 & M4 & M5 & M6 & M7 & M8 & M9 \\
\hline \multirow[t]{2}{*}{ Constant } & -0.44 & -0.8 & -0.64 & -0.38 & -0.78 & & 0.38 & -0.79 & -1.02 \\
\hline & $(-1.02)$ & $(-1.21)$ & $(-1.08)$ & $(-1.12)$ & $(-0.60)$ & & $(-0.89)$ & $(-0.78)$ & $(-0.61)$ \\
\hline \multirow[t]{2}{*}{ DOM } & $1.34^{* * *}$ & $1.05^{* *}$ & $0.96^{* *}$ & $1.21^{* * *}$ & $0.91^{* *}$ & 0.79 & $1.24^{* *}$ & $0.94^{*}$ & 0.85 \\
\hline & $(4.27)$ & $(2.87)$ & $(3.93)$ & $(5.12)$ & $(3.24)$ & $(1.29)$ & $(2.20)$ & $(1.59)$ & $(0.47)$ \\
\hline \multirow[t]{2}{*}{ DOP } & -0.71 & $-1.12^{* * *}$ & -1.15 & $-0.55^{\star * *}$ & $-0.97^{\star * *}$ & $-0.65^{\star}$ & $-0.44^{*}$ & $-0.88^{* *}$ & $-0.94^{* *}$ \\
\hline & $(-1.54)$ & $(-4.74)$ & $(-1.87)$ & $(-5.01)$ & $(-5.76)$ & $(-1.98)$ & $(-.1 .88)$ & $(-3.53)$ & $(-2.35)$ \\
\hline \multirow[t]{2}{*}{ SOI } & & $1.70^{* * *}$ & $1.72^{\star *}$ & & $1.86^{* * *}$ & $2.7181^{\star *}$ & & $1.89^{* *}$ & $1.89^{*}$ \\
\hline & & $(3.34)$ & $(2.65)$ & & $(4.05)$ & $(2.68)$ & & $(2.68)$ & $(1.28)$ \\
\hline \multirow[t]{2}{*}{ OPEN } & & & -1.51 & & & 0.93 & & & -1.88 \\
\hline & & & $(0.61)$ & & & $(0.53)$ & & & $(0.56)$ \\
\hline \multirow[t]{2}{*}{ Rho } & $0.26^{* * *}$ & $0.26^{* * *}$ & $0.23^{* *}$ & $0.32^{* * *}$ & $0.29^{* * *}$ & $0.306^{*}$ & $0.211^{* *}$ & $0.18^{* *}$ & 0.15 \\
\hline & $(6.43)$ & $(5.56)$ & $(4.94)$ & $(4.87)$ & $(5.74)$ & $(2.75)$ & $(3.80)$ & $(3.77)$ & $(1.66)$ \\
\hline $\begin{array}{c}\text { P value of } \\
\text { Hauseman_ts }\end{array}$ & 0.41 & 0.36 & 0.98 & 0.93 & 0.62 & 0 & 0.76 & 0.73 & 0.43 \\
\hline Random/Fixed & re & re & re & re & re & $\mathrm{fe}$ & re & re & re \\
\hline
\end{tabular}


indicating that the overflow mode of innovation efficiency is more dependent on the geographical distance. The two geographical regions are closer to each other, the flow of innovation elements is more convenient, the exchange of innovation activities is more frequent, and the characteristics of high externality of innovation strengthen the radiation effect of adjacent areas; while the network behavior of different regions is similar to innovation. The role, but the effect is relatively less than the impact of geographical proximity.

2) The regression coefficients of the degree of marketization in M1 - M9 are positive. Except for M6 and M9, the significance test is passed, which indicates that the degree of marketization has a significant effect on the improvement of innovation efficiency. Firstly, the degree of marketization is high. Locally, there is less government interference in resource allocation, which reduces the cost of rent-seeking enterprises and helps enterprises reduce operating costs. The marketization process of Guangdong-Hong Kong-Macao Greater Bay Area has been in the forefront of the country. Its relatively perfect market-oriented institutional conditions provide enterprises with a level playing field. Under the constraints of maximizing profits and minimizing costs, the fierce competitive environment forces marketization. The main body innovates and continuously improves the efficiency of innovation; many domestic mobile phone manufacturers such as Huawei have grown up in this fierce competitive environment, and finally ushered in the perfect counterattack of domestic mobile phones in domestic and foreign markets; at the same time, they are relatively fair and transparent. The market environment has reduced the asymmetry of information, promoted the flow and agglomeration of innovative resources, and reduced the mismatch probability of innovation resources. The innovation resources of Guangdong-Hong Kong-Macao Greater Bay Area are mainly concentrated in three core cities of Shenzhen, Hong Kong and Guangzhou. The concentration of related industries promotes the division of labor and cooperation between industries, forms a complete innovation ecosystem and industrial chain, and further enhances the efficiency of the allocation of innovative resources through economies of scale.

3) The regression coefficient of economic density in M1-M9 is significantly negative, indicating that the economic density of Guangdong-Hong Kong-Macao Greater Bay Area is at a relatively high level and has an innovative suppression effect; the adverse consequences of high economic density are on the one hand another aspect is innovation redundancy. Areas with high economic density rely on siphon effect to become a gathering area of innovation factors, but excessive factor aggregation may cause cost to rise sharply. One of its performances is that population agglomeration brings about an increase in housing costs, which increases the cost of innovation input and inhibits innovation. In the input-output stage, the efficiency is improved; the other party's innovation factor agglomeration makes the scale of innovation investment increase rapidly, but its local market size cannot increase in the same proportion, which reduces the conver- 
sion efficiency of innovation results. M2, M5, and M8 indicate that the industrial structure has a significant role in promoting the improvement of innovation efficiency. This is similar to the results of many studies; the more developed the industrial structure, the better the development of the service industry represented by finance, in the early days of technology, financial Development can accelerate the diffusion of technology (Comin \& Nanda, 2014), and the financial system can provide financial support for technological advancement and diversify the risks faced by companies in research and development activities. M3, M6, and M9 show that the impact of openness on the innovation efficiency of Guangdong-Hong Kong-Macao Greater Bay Area is not significant. This may be because the cities in Greater Bay Area have little difference in the degree of openness, and their degree of opening up is already relatively high. Level, innovation efficiency is not sensitive to the improvement of openness.

In order to explore the regional differences, the cities of Guangdong-Hong Kong-Macao Greater Bay Area will be divided into two groups according to geographical location (including: Guangzhou, Shenzhen, Hong Kong, Dongguan, Huizhou); West Bank (including: Zhuhai, Foshan, Zhongshan, Jiangmen), Zhaoqing, Macau) two groups. According to the degree of innovation resource endowment, it is divided into two groups: First (including Shenzhen, Guangzhou, Hong Kong, Zhuhai, Foshan); Second (including Dongguan, Huizhou, Zhongshan, Jiangmen, Zhaoqing, Macao). The regression results are as follows.

From M1 and M4 in Table 5, there is a clear difference in the spatial effect of

Table 5. SAC model grouping regression results.

\begin{tabular}{|c|c|c|c|c|c|c|c|}
\hline \multirow{2}{*}{ Group Variable } & \multicolumn{2}{|c|}{ East } & \multicolumn{2}{|c|}{ West } & \multicolumn{2}{|c|}{ First } & \multirow{2}{*}{$\begin{array}{c}\text { Second } \\
\text { M7 }\end{array}$} \\
\hline & M1 & M2 & M3 & M4 & M5 & M6 & \\
\hline \multirow[t]{2}{*}{ Constant } & -0.69 & & $-1.18^{*}$ & $-1.33^{*}$ & -0.52 & 2.18 & 2.22 \\
\hline & $(-0.45)$ & & $(-1.55)$ & $(-2.09)$ & $(-0.89)$ & $(-0.88)$ & $(-0.34)$ \\
\hline \multirow[t]{2}{*}{$\mathrm{DOM}$} & 0.58 & 0.2 & $1.64^{* * *}$ & $1.75^{\star * *}$ & 1.65 & 0.93 & -1.26 \\
\hline & (1.13) & $(0.65)$ & $(3.45)$ & $(4.12)$ & $(0.56)$ & $(0.15)$ & $(0.45)$ \\
\hline \multirow[t]{2}{*}{ DOP } & -0.54 & -1.15 & $0.31^{* * *}$ & $0.29^{* *}$ & -0.97 & -2.75 & 2.67 \\
\hline & $(0.41)$ & $(0.98)$ & $(3.48)$ & $(2.76)$ & $(0.66)$ & $(0.45)$ & $(0.98)$ \\
\hline \multirow[t]{2}{*}{ SOI } & $2.60^{* * *}$ & $4.33^{\star *}$ & $1.31^{* * *}$ & $1.55^{\star * *}$ & 0.32 & -0.62 & -0.27 \\
\hline & $(5.43)$ & $(2.45)$ & $(7.23)$ & $(8.67)$ & $(1.09)$ & $(1.44)$ & $(1.23)$ \\
\hline \multirow[t]{2}{*}{ OPEN } & & -2.55 & & -0.88 & & -16.07 & \\
\hline & & $(0.12)$ & & $(0.33)$ & & $(0.27)$ & \\
\hline \multirow[t]{2}{*}{ Rho } & $0.00^{* * *}$ & 0.09 & -0.1 & $-0.12^{\star *}$ & & & \\
\hline & $(2.56)$ & $(0.88)$ & $(0.85)$ & $(1.75)$ & & & \\
\hline $\mathrm{R}^{2}$ & 0.24 & 0.19 & 0.18 & 0.21 & 0.18 & 0.23 & 0.15 \\
\hline $\begin{array}{c}\text { P value of } \\
\text { Hauseman_ts }\end{array}$ & 0.7 & 0.019 & 0.87 & 0.99 & 0.72 & 0.21 & 0.32 \\
\hline Random/Fixed & re & $\mathrm{fe}$ & re & re & re & re & re \\
\hline
\end{tabular}


innovation efficiency between the east and the west. For the East Coast, innovation efficiency has a positive spatial spillover effect, that is, the improvement of innovation efficiency in a region can significantly promote the innovation efficiency of surrounding areas. The improvement is concentrated in the area of high efficiency in space; but for the West Bank, the spatial effect of innovation efficiency is not so obvious compared to the East Coast, and there is an opposite effect, and the innovation efficiency of a region is improved. On the contrary, it has restrained the improvement of innovation efficiency in the surrounding areas. This phenomenon may be because the innovation level of the cities in the West Bank is at a relatively low level, and the level of innovation capability between cities is not much different. The cities at the same level are attracting. In terms of innovation factors, it is in a serious competitive relationship, lacking a core city that can radiate the innovation and development of surrounding cities, so as to promote complementary cooperation between cities. For the East Coast, the innovation and development of Dongguan and Huizhou have deeply benefited from the radiation effect of innovative core cities such as Shenzhen, and have become the hinterland supporting the development of Shenzhen's high-tech industry, and have taken over the transfer of high-tech manufacturing from Shenzhen, collaborative and innovative relationship of cooperation and win-win. From the regression coefficient of the degree of marketization, marketization has a significant role in promoting the improvement of innovation efficiency, and it has regional differences, and the promotion effect of marketization in the West Bank is more obvious. From the regression coefficient of economic density, economic density has a significant inhibitory effect on the innovation efficiency of the East Coast, and has a significant role in promoting the innovation efficiency of the West Bank. This shows that the impact of economic density on innovation efficiency has a threshold effect. When the economic density exceeds a certain level, it has an inhibitory effect on the innovation effect. This conclusion is similar to Chen Shuyun's (2017) impact on population density on innovation efficiency. The regression coefficient of SOI in M1-M4 indicates that there is a certain regional difference in the impact of industrial structure on innovation efficiency. The development level of service industry such as East Coast Finance is higher than that of West Bank, and its impact on innovation efficiency is significantly higher than that of West Bank. The conclusions obtained by the First and Second groups are basically similar in the above analysis, but the spatial effects are not significant, so the model is not estimated by the spatial measurement method.

\section{Conclusion and Revelation}

This paper uses Malmquist to measure the innovation efficiency values of the cities in Guangdong, Hong Kong and Macao, and on this basis, it demonstrates the relationship between the marketization process and the innovation efficiency of Guangdong-Hong Kong-Macao Greater Bay Area. It is found that the im- 
provement of marketization process has significantly promoted the Guangdong, Hong Kong and Macau Bay. There is a regional difference in the innovation efficiency of the district, and the promotion effect of marketization on innovation efficiency. At this stage, the marketization effect on the innovation efficiency of the west coast of Guangdong, Hong Kong and Macao is more obvious. At the same time, we incorporate some factors such as economic density, openness, and industrial structure as control variables into the model, and find that the economic density has a threshold effect on the improvement of innovation efficiency. For the west bank cities of Guangdong-Hong Kong-Macao Greater Bay Area with low economic density, economic density tends to promote innovation efficiency, while for high-density East Coast cities, economic density is just the opposite of innovation efficiency. Of course, for the Greater Bay Area of Guangdong and Hong Kong with high population concentration, the economic density is against Greater Bay Area. The improvement of innovation efficiency has a significant inhibitory effect. In addition, similar to the findings of other scholars, the role of industrial structure in innovation effects is also positive. The only difference is that this article does not find that openness has a significant impact on innovation effects, which may be due to opening in the cities of Greater Bay Area, Guangdong, Hong Kong and Macao. The difference in degree is small, so standing inside the Greater Bay Area of Guangdong and Hong Kong, the change in innovation efficiency is not obvious.

Based on the above research conclusions, we have the following inspirations: First, we must further deepen the market-oriented reforms, and let the market play a decisive role in the allocation of innovative resources; vigorously develop the non-state-owned economy and reduce the barriers for private enterprises to enter monopoly industries; fully attach importance to and play the role of SMEs in independent innovation; establish a sound system of property rights protection to create a fair and transparent competitive environment for enterprises; in order to better play the spillover effect of innovation, the region should realize the full flow of innovation factors, especially the talent resources, for the Guangdong, Hong Kong and Macau It is said that "one country, the characteristics of the two systems", so how to break through the administrative barriers between regions and deepen the cooperation between the inland cities and Hong Kong and Macao is especially important to improve the overall innovation strength of Guangdong, Hong Kong and Macau..

Finally, the following limitations exist in this article. First, marketization is a complex concept that contains too many factors, so measuring the marketization process from the perspective of the proportion of the state-owned economy has certain limitations. Second, this article only reveals the promotion effect of marketization process on innovation efficiency. However, the specific path of how marketization promotes innovation efficiency is still unknown. However, the specific path of how marketization promotes innovation efficiency is still unknown, so an important aspect of future research is the study of the specific path 
of marketization affecting innovation efficiency. So an important aspect of future research is the study of the specific path of marketization affecting innovation efficiency.

\section{Conflicts of Interest}

The author declares no conflicts of interest regarding the publication of this paper.

\section{References}

Chen, J., \& Dai, M. (2018). Regional Corruption, Risk Avoidance and Innovation Redundancy-Also on the Test of Corruption "Suppression Theory" and "Promotion Theory". Economic and Social Systems, No. 2, 69-80.

Chen, S. Y., \& Yang, J. K. (2017). Can Population Agglomeration Promote Regional Technology Innovation? An Empirical Study of Provincial Panel Data from 2005 to 2014. Science \& Technology Progress and Policy, 34, 45-51.

Cheng, L. W., \& Sun, W. (2012). The Influence of Marketization Degree on the Efficiency of Independent Innovation Allocation-Analysis of Panel Data of High-Tech Industry Based on Cost-Malmquist Index. China Soft Science, No. 5, 128-137.

Ciccone, A., Cingano, F., Cipollone, P. et al. (2006). The Private and Social Return to Schooling in Italy. Giornale Degli Economisti E Annali Di Economia, 63, 413-448. https://doi.org/10.2139/ssrn.895463

Comin, D., \& Nanda, R. (2014). Financial Development and Technology Diffusion. Harvard Business School Entrepreneurial Management Working Paper, No. 15, 15-36. https://doi.org/10.2139/ssrn.2520551

Dai, K. Z., \& Liu, Y. J. (2013). The Impact of Marketization Process on Innovation Efficiency and Industry Difference-An Empirical Test Based on China's High-Tech Industry. Journal of Finance and Economics, 39, 4-16.

Deng, Q., \& He, A. P. (2017). Urban-Rural Income Gap, Labor Quality and Economic Structure Transformation-An Empirical Study from Chinese Provincial Data. Social Sciences Research, No. 6, 22-30.

Fan, G., \& Wang, X. L. (2011). Contribution of China's Marketization Process to Economic Growth. Economic Research, 46, 4-16.

Fan, G., \& Wang, X. L. (2011). Contribution of China's Marketization Process to Economic Growth. Economic Research, 46, 4-16.

Farrell, M. J. (1957). The Measurement of Productive Efficiency. Journal of the Royal Statistical Society, 120, 252-290. https://doi.org/10.2307/2343100

Ge, D. Y. (2018). Research on Industrial Diversity, Economic Density and Urban Innovation Ability. Shanghai: East China Normal University.

Guan, J. C., \& Chen, K. H. (2009). Measurement of Technological Innovation Efficiency of High-Tech Industry in China. Quantities Economics \& Technology Research, 26, 19-33.

Han, J. (2010). Research on Innovation Efficiency of China's High-Tech Industry-An Empirical Analysis Based on SFA Method. Science Research, 28, 467-472.

Huang, H., \& Xu, C. (1998). Soft Budget Constraint and the Optimal Choices of Research and Development Projects Financing. Journal of Comparative Economics, 26, 62-79. https://doi.org/10.1006/jcec.1997.1508 
Kan, D. (2013). Foreign Trade, Marketization Process and Technological Innovation of Domestic-Funded Enterprises-An Empirical Study Based on Panel Data of Provincial Large and Medium-Sized Industrial Enterprises. Journal of Central University of Finance and Economics, No. 10, 57-62.

Scherer, F. M. (1957). Market Structure and the Employment of Scientists and Engineers. American Economic Review, 57, 524-531.

Schumpeter, J. A., \& Nichol, A. J. (1934). Robinson's Economics of Imperfect Competition. Journal of Political Economy, 42, 249-259. https://doi.org/10.1086/254595

Segal, D. (1976). Are There Retums to Scale in City Size? Review of Economics Statistics, 58, 339-350. https://doi.org/10.2307/1924956

Shi, Z. K., \& Wang, M. C. (2016). China's Marketization Process and Economic Growth: An Empirical Analysis Based on Bayesian Model Average Method. Economic Review, No. 1, 26-38.

Sun, Z., Liu, L. H., \& Sun, Y. Z. (2014). The Degree of Marketization, Local Protectionism and the Spillover Effect of R \& D-Evidence from Chinese Industry. Management World, No. 8, 78-89.

Villard, H. H. (1958). Competition, Oligopolyand Research. Journal of Political Economy, 66, 483-497. https://doi.org/10.1086/258101

Wang, H., Lai, M. Y., \& Qi, J. Y. (2010). International Technology Transfer, Heterogeneity and Research on Technological Innovation of Chinese Enterprises. Management World, No. 12, 131-142.

Wu, Y. B. (2006). R \& D and Productivity-An Empirical Study Based on Chinese Manufacturing Industry. Economic Research, No. 11, 60-71.

Yang, F. Q., \& Cheng, K. (2018). Financial Development, Science and Technology Innovation and Import and Export Trade-An Empirical Analysis Based on Provincial Panel Data. Technology Economics and Research, No. 8, 71-77.

Zhao, Z. Y., Zhou, J. J., \& Shen, N. (2016). An Empirical Study on the Impact of Financial Development and Regional Innovation Efficiency-Intermediary Effect Based on Openness. Scientia Research, 34, 1408-1416.

Zhu, H. Y., \& Wang, W. P. (2015). Environmental Regulation, Opening to the Outside World and Independent Innovation-An Empirical Study Based on Provincial Dynamic Panel Data. Exploration of Economic Problems, No. 12, 33-44. 